\title{
Facial Mass Impending the Visual Axis: A Case Report about a Congenital Frontonasal Meningoencephalocele
}

Théra $\mathrm{JP}^{1^{*}}$, Dakouo $\mathrm{P}^{1}$, Konipo $\mathrm{A}^{1}$, Tiama JML ${ }^{1}$, Tinley $\mathrm{C}^{2}$

${ }^{1}$ Institute of African Tropical Ophthalmology, Bamako Mali

${ }^{2}$ Pediatric Ophthalmologist, Consultant CCBRT Hospital, Dar Es Salam Tanzania

DOI: $10.36347 /$ sjmcr.2020.v08i03.022

| Received: 19.02.2020 | Accepted: 26.02.2020 | Published: 18.03.2020

*Corresponding author: Dr. Japhet Pobanou Thera

\section{Abstract}

Meningocele is a hernial protrusion of part of meninges and neural elements in a sac. It is a rare medical condition particularly the facial form. A full-term female baby was brought to our office for congenital facial mass. The mass was diagnosed as a frontonasal meningoencephalocele.

Keywords: Facial mass, visual axis, meningoencephalocele.

Copyright @ 2020: This is an open-access article distributed under the terms of the Creative Commons Attribution license which permits unrestricted use, distribution, and reproduction in any medium for non-commercial use (NonCommercial, or CC-BY-NC) provided the original author and source are credited.

\section{INTRODUCTION}

Congenital midline facial masses are rare malformations, occurring with an incidence of one case in 20 to 40,000 births [1]. We report a case of frontonasal meningoencephalocele in a three-day-old infant.

\section{CASE Report}

It was a newborn female weighing 3,200 g, in whom we found a soft frontonasal mass measuring 60 $\mathrm{mm}$ long slightly compressing the left eye (fig 1). The child proceeded from a normal delivery where two prenatal consultations were done. The 27-year-old primiparous mother with no specific history did not undergo ultrasound exam during her pregnancy. The ophthalmic examination found a slight obstruction of the left palpebral slant. He was cyanotic and was resuscitated at birth. Orbito-cerebral computed tomography (CT) confirmed a frontal meningoencephalocele (fig 2).

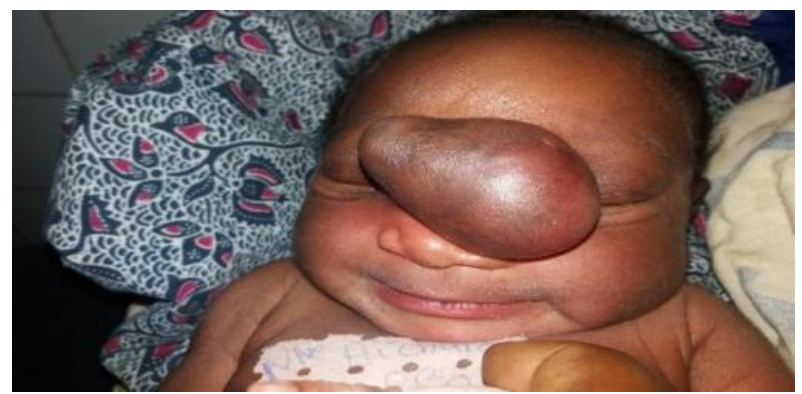

Fig-1: Photograph of the child child

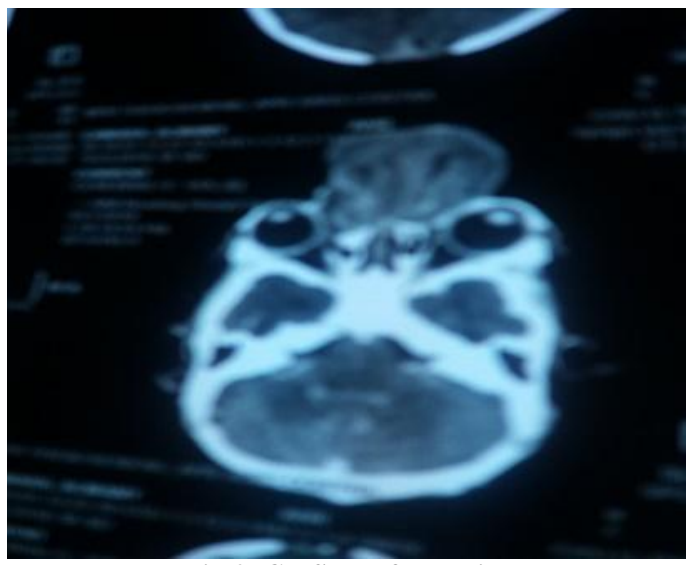

Fig-2: CT-Scan of the child

\section{DISCUSSION}

The meningoencephaloceles are congenital anomalies characterized by a hernia of the meninges and the cerebral parenchyma out of the cranial box through a bone defect $[1,2]$.

Njamnshi et al. [3] reported in Cameroon, an incidence of 2 cases per 1000 births against 0.95 per 1000 births found by Ugwu RO et al. [4] in Nigeria. They are occipital in $75 \%$ of the cases and involve the midline in $90 \%$ of the cases [1].

Etiologically, the real cause of these anomalies is not known with certainty. Environmental teratogens, hyperthermia during pregnancy, low economic status, and nutritional status are suspected $[5,6]$. 
In $60 \%$ [7] there is an association of chromosomal abnormalities or craniofacial malformations. Mbassi et al. reported an association with hydrocephalus [8]. In our case no other malformation was associated.

\section{Conclusion}

Rare congenital pathologies, meningoencephaloceles should be suspected in any case of congenital nasal mass of the midline. Brain imaging is critical to confirming the diagnosis.

\section{REFERENCES}

1. Lowe Lisa H, Booth Timothy N, Joglar Jeanne M, Rollins Nancy K, Midface anomalies in children. RadioGraphics. 2000 ; 20 :907-922.

2. Kennard CD, Rasmussen J. Congenital midline nasal masses : diagnosis and management. J Dermatol Surg Oncol. 1990; 16 :1025-1036.

3. Njamnshi AK, Djientcheu V, Lekoubou A, Guemse M, Obama MT, Mbu R. Neural tube defects are rare among black Americans but not in subSaharan black Africans: the case of YaoundeCameroon. J Neurol Sci. 2008; 15 :270.

4. Ugwu RO, Eneh AU, Oruamabo RS. Neural tube defects in a university teaching hospital in southern Nigeria: trends and outcome. Niger J Med. 2007; 16(4):368-71.

5. Butler N, Benham, DG. Perinatal Mortality: the first report of the british perinatal mortality survey. E and S. Livingston Lid. Edinburgh and London; 1963.

6. Hendricks CH obstet. Gyneco. 1955; $6: 592$

7. Holmes AD, Meara JG, Kolker AR, Rosenfeld JV, Klug GL Frontoethmoidal encephaloceles: reconstruction and refinements. J Craniofac Surg. 2001; 12(1):6-18.

8. Mbassi AHD, Pondy A, Mah E, Kana SP, Eloundou NJ, Koki NPO, Méningo-Encéphalocèle Sincipitale chez un Nourrisson de 6 Semaines: une Cause Rare de Masse Faciale Congénitale. Health Sci. 2013; 14(3). 